\title{
EL GÉNERO LITERARIO: EPISTEMOLOGÍA Y JUSTIFICACIÓN EN ORTEGA Y GASSET
}

\author{
Enrique FERRARI NIETO \\ Universidad de Valladolid \\ eferrari79@gmail.com
}

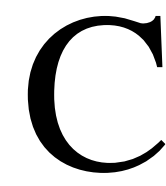

on la convulsión que produce la publicación de la Estética de Croce, Ortega abre una brecha para reconducir el rechazo de algunos a los géneros literarios, que entienden desde una perspectiva estrictamente formal, la de la preceptiva clásica, hacia una propuesta tangencial (poco anclada en las formas) en la que estas categorías estéticas pasan a ser herramientas epistemológicas específicas. Con un recorrido parecido al de la Ilustración alemana, con Hegel, que llevó la tipología clasicista a la cuestión filosófica de las referencias, como formas relacionales de la experiencia, entre lo objetivo y lo subjetivo. Porque, para buscar su sitio en la discusión que reabre el italiano, habla de esencia («Acaso anda fuera de la moda disertar sobre la esencia de los géneros literarios»), y marca la profundidad que quiere en el tema, para alejarlo de retóricas (I, 365) ${ }^{1}$. Escribe: «Cada arte es necesario y consiste en expresar por él lo que la humanidad no ha podido ni podrá jamás expresar de otra manera» (I, 475-476). Frente a Croce ${ }^{2}$ y otros que niegan su existencia, como Unamuno en España, Ortega (primero en 1910, muy cerca todavía del neokantiano Cohen, y luego en sus Meditaciones del Quijote de 1914) cree en la utilidad de los géneros literarios. Aunque sólo fuera como método. Como en la zoología. Porque la obra de arte, dice, es individual, pero el género literario es un buen modo de aproximación, como un repertorio limitado de posibilidades (III, 388): «De la misma suerte que necesita la

\footnotetext{
${ }^{1}$ Las referencias a los trabajos de Ortega y Gasset remiten a sus Obras completas, editadas en Alianza Editorial, en su edición de 1983. El número en romano indica el tomo y los números arábigos la página.

${ }^{2}$ Aunque en 1911 Ortega reconoce a Croce como ejemplo y orientación (en términos muy generales, muy vagos, en su papel de intelectual en una Italia convulsa) (X, 184), en cuestiones concretas, que son unas pocas notas, ataca sus planteamientos. En "Cultura y culturas", de 1924, arremete contra su filosofía neohegeliana: una de las filosofías de la cultura, «síntesis urgentes, arbitrarias, de una convencional estructura, sórdidas utopías en que se confunde la sinuosa y espléndida realidad con los míseros esquemas del llamado idealismo» (III, 253).
} 
biología del concepto de especie para aproximarse al individuo orgánico, ha menester la estética descriptiva del concepto del género literario para acercarse al libro bello» (II, 122), escribe en "Una primera vista sobre Baroja", en 1910. Pero su clasificación no se atiene a los rasgos formales que determinan la vieja concepción poética. Cada definición lleva más allá la significación de la estructura formal para implicarla con el fondo en un modo de decir único: de -como dejó escrito Aristóteles- poner ante los ojos directamente los hechos (Poet 1455a24-25). De la lírica, por ejemplo, escribe en Meditaciones del Quijote: «No es un idioma convencional al que puede traducirse lo ya dicho en idioma dramático o novelesco, sino a la vez una cierta cosa a decir y la manera única de decirlo plenamente» (I, 366). Su defensa no es la de la antigua poética, para la que los géneros literarios eran, dice, unas reglas de creación a las que había que ajustarse, como esquemas vacíos: instituciones fijas y cerradas, regidas por leyes inamovibles, con un fin jerarquizador, como señalan García Berrio y Huerta Calvo (1992: 87). Para Ortega son verdaderas categorías estéticas, temas radicales irreductibles entre sí. No se trata de una supeditación del fondo a la forma. Sino de que forma y fondo son inseparables, y que este fluye sin las contenciones de la forma. Escribe en su libro de 1914: «Hay en la forma lo mismo que había en el fondo; pero en aquella está manifiesto, articulado, desenvuelto, lo que en este se hallaba con el carácter de tendencia o pura intención. De aquí proviene la inseparabilidad entre ambos; como que son dos momentos distintos de una misma cosa» (I, 365-366). Lo que continúa, con una nota a pie de página en su edición, Julián Marías (Ortega y Gasset, 1990: 181, n. 6): el género literario consiste en la generación de la obra partiendo de su tema, en su génesis: la vía, con el fondo de un tema preciso, por la que se engendra la obra correspondiente.

El género que mejor conoce es la novela, con la que se atreve con una preceptiva formalista en su Ideas sobre la novela, que publica con La deshumanización del arte en 1925. Pero remite también, sin ninguna exhaustividad (Salas Fernández, 1994: 544), a otros, híbridos, como decía Lessing, fuera de la tríada rígida de la lírica, la épica y la dramática, sin una caracterización formal. Algunos: Que no han podido lograr su independencia, como el diálogo, que nace de la comedia (I, 388). O muy recientes, como el esperpento, bautizado y acotado por Valle-Inclán (V, 247). O fracasados: como la lata: una narración de algo que no interesa (I, 378). O con una dimensión metafísica: como la vida humana, faena poética, en la que el hombre es novelista de sí mismo (VIII, 29). Y otros: interesantes sugerencias del propio Ortega, como la impertinencia, por ejemplo. Aunque es solo una nota, en "Viaje de España", en 1910, al margen de su comentario a Meier-Graefe ${ }^{3}$, sobre su desconocimiento de España a pesar de su libro.

\footnotetext{
${ }^{3}$ Ortega le dedica al historiador y crítico alemán (1867-1935) dos artículos: "Meier-Graefe", en 1908, y "Viaje de España", en 1910, a raíz de un libro con el mismo título del crítico alemán. Lo presenta como
} 
La define como un género literario (el género más espontáneo en su tiempo) marcado por el desdén: «Lo impertinente de la impertinencia -explica el madrileño- no consiste en que alguien nos diga palabras enojosas, sino en que estas sirven al impertinente como medio de demostrarnos que no existimos para él. La impertinencia es el desdén perfecto, el desdén que anonada al desdeñado y le suprime del mundo de las realidades» (I, 529). O la náusea: un género literario con el que se refiere sólo a los artículos de Victoria Ocampo: por su estilo espasmódico con que ataca una injusticia o un desmán (VIII, 384), escribe en "Ictiosaurios y editores clandestinos".

Ocampo, ensayista argentina educada en Francia, publicó con 33 años su primer libro, De Francesca a Beatrice: un estudio sobre la Divina Comedia, de Dante, del que Ortega escribe un epílogo (cfr. Campomar, 2001). Fue anfitriona en su país, con la revista Sur detrás, de grandes personajes de la cultura de su tiempo. Y Ortega, que la conoce bien, le dedica unas palabras elogiosas, galantes, en las notas de dos de sus trabajos: Es -certifica- entusiasta de perfección, de gusto certero y riguroso y con un gran fervor hacia toda disciplina severa (III, 333). «Escribe con una prosa -continúa, con los rasgos que debe tener presentes una novela, en "Epílogo al libro De Francesca a Beatrice"- tan muelle, y lleva cada frase un resorte suave, que nos despide elásticamente de la tierra y nos proporciona una ascensión» (III, 334). Pero su prosa queda fuera del género literario que encaja mejor con la mujer, dice: la epístola. Porque, con sólo una anotación, en "La poesía de Ana de Noailles", en 1923, vincula los rasgos propios de este género, su atención al destinatario, con el sexo del escritor. Es la única forma privada de la literatura $\mathrm{y}$, por tanto, señala, el género literario donde han destacado las mujeres y fracasado los hombres. Parte de sus postulados en torno a las diferencias entre hombre y mujer: el ámbito masculino es lo público, y el femenino lo privado. Por eso el hombre, incapaz de mostrarse íntimo, en la epístola escribe con gestos de escenario. Y la mujer, cuando el público no responde a ese carácter privado del género epistolar, revela que su intimidad, tan deliciosa bajo la luz de un interior, es muy pobre: la personalidad de la mujer, dice, es poco personal. La mujer es un género más que un individuo (IV, 433). La mujer, escribe en "La Gioconda" de 1911, se ha apropiado del papel de musa; un modo, dice, de hacerse necesaria al hombre (I, 556). Así, los críticos de arte rastrean, en la obra del artista, las mujeres que han influido en su vida y en sus pinturas o sus libros. Pero la musa no es eso. La mujer no es necesaria para el hombre. En cambio, sí hay una supeditación (deseada) de la mujer a este. Es el

“impresionista exacerbado, díscolo y terrible" (I, 97). Como «sutil pensador, artista entusiasta, capaz de inagotables ardores» (I, 531). Una primera línea en la defensa de una verdad artística que no explica. Pero que ejemplifica en su ataque a Boecklin, el pintor alemán más famoso -escribe- que ha favorecido la mentira imperial. Meier-Graefe ha sido, dice, quien ha mostrado el impresionismo de los viejos pintores españoles, del que los pintores del siglo XIX han bebido «las más hondas enseñanzas de veracidad estética» (I, 98). 
cristal transparente de hermosura de Cervantes, destinada a ser un tránsito de otros. Se constituye a partir de su vocación de entrega; disposición que se acopla perfectamente al impulso masculino de apoderarse de otra persona: «La esencia de la feminidad se revela -escribe el filósofo en "Esquema de Salomé" de 1921- en el hecho de que un ser sienta realizado plenamente su destino cuando entrega su persona a otra persona» (II, 360). La percepción del intracuerpo marca las diferencias entre ambos sexos, el rango vital inferior de la mujer. No es lo normal, señala, cortar el diálogo con el entorno y centrar la atención sobre uno mismo. Es patológico, aunque esa penetración en lo psíquico pueda facilitar el descubrimiento de valores, asociados a la intimidad, muy estimados. Y es la mujer la que posee más vida interior (II, 458-459): «Es un hecho notorio que el cuerpo femenino está dotado de una sensibilidad interna más viva que el del hombre, esto es, que nuestras sensaciones orgánicas intracorporales son vagas y como sordas comparadas con las de la mujer» (VI, 161). El hombre es una persona racional. Y el intelecto un órgano de virilidad. El centro del alma femenina, en cambio, cree Ortega, está ocupado por un poder irracional en el que no interviene la lógica.

Para mujer y hombre, para establecer sus cualidades, que se adecuan a su situación en el mundo, busca imágenes en el teatro, sobre todo en "Revés de almanaque", en 1930. Escribe en "Divagación ante el retrato de la marquesa de Santillana”, de 1918: «La mujer tiene un exterior teatral y una intimidad recatada; en el hombre es la intimidad lo teatral. La mujer va al teatro; el hombre lo lleva dentro» (II, 689). El hombre es el actor y la mujer el público en una nueva versión de esa metáfora básica en su metafísica, con la vida (la persona en su confrontación con la circunstancia) como realidad radical. $\mathrm{Y}$ estos papeles de hombre y mujer en el teatro indican su idoneidad para los diferentes géneros literarios. La lírica es un género masculino, por ese instinto de expansión, de manifestación; por su afán de confesión pública, de evidenciar su ser más íntimo. Tiene una capacidad innata para ello: su intimidad vale para la ostentación. En cambio, la mujer, que es hermética en el contacto con el público, y que se oculta y reserva su intimidad a un solo hombre, es la única apta para el género epistolar, única forma privada de la literatura. El hombre está incapacitado para este género, porque no es capaz de mantener la intimidad y gesticula como en un escenario. La mujer no puede con la lírica: su intimidad, en público, resulta siempre pobre, porque carece de personalidad. Es más bien, escribe Ortega, un género que un individuo (IV, 433).

Prueba una definición para el lirismo, en Meditaciones del Quijote: «Es una proyección estética de la tonalidad general de nuestros sentimientos» (I, 391), con unos rasgos que lo vinculan a uno solo de los sexos. Sólo el hombre -cree en "Divagación ante el retrato de la marquesa de Santillana"- es capaz de lírica, por su cinismo varonil, 
por ese instinto de expansión, de manifestación que lo lleva a confesarse ante los demás (II, 689). La mujer no puede poseer genialidad lírica porque carece de la capacidad innata de exteriorizar lo íntimo de la persona. Lo explica en "La poesía de Ana de Noailles": «[El lirismo] supone una innata capacidad para lanzar al universo lo íntimo de nuestra persona. Mas, por lo mismo, es preciso que esta intimidad nuestra sea apta para semejante ostentación. Un ser cuyo secreto personal tenga más o menos carácter privado producirá una lírica trivial y prosaica. Hace falta que el último núcleo de nuestra persona sea de suyo como impersonal y esté, desde luego, constituido por materias trascendentes» (IV, 432-433). La lírica nace para ser vista desde fuera: no colisiona con la vida; aparece contrapuesta a ella, mostrando con olímpica inocencia su irrealidad (III, 413). Como una mónada (III, 570). Había escrito en 1914 que es: «una cierta cosa a decir y la manera única de decirlo plenamente» (I, 366).

Pero el único género vivo en su tiempo es la novela. El arte es interpretación de lo humano, afirma. Y cada género literario es un cauce abierto por el hombre en ese intento de explicarse: una confesión que tiene sus preferencias en cada época (I, 391). En la suya, la novela, intuye Ortega, es el único género literario que existe; y es su estructura, rigurosa e inquebrantable, dada por el género, la que le confiere esa dignidad (III, 545). Para su definición se queda con tragicomedia ${ }^{4}$, el término con que Fernando de Rojas presenta su Celestina: lo que originariamente es una obra dramática con rasgos de comedia y de tragedia, que se adecua bien a un género que es, para Ortega y Gasset, «de intención crítica y cómico nervio» (I, 398). Escribe en Meditaciones del Quijote: «La línea superior de la novela es una tragedia; de allí se descuelga la musa siguiendo a lo trágico en su caída. La línea trágica es inevitable, tiene que formar parte de la novela, siquiera sea como el perfil sutilísimo que la limita. Por esto, yo creo que conviene atenerse al nombre buscado por Fernando de Rojas para su Celestina: tragicomedia. La novela es tragicomedia. Acaso en la Celestina hace crisis la evolución de este género conquistando una madurez que permite en el Quijote la plena expansión» (I, 397). Con el diálogo como principio unitivo. Como el instrumento con que se articula. Como explica, muy breve, en su temprano "Adán en el Paraíso", de 1910: en los siglos XV y XVI el hombre descubre lo subjetivo, lo psicológico, que se presenta como un mundo fugaz de emociones, que fluye en el tiempo: lo opuesto a lo estático, lo firme, que ha atendido hasta entonces la épica. Su expresión estética será la novela, que alude -con el diálogo, que es el que permite tejer sus materiales en la apariencia fluida del tiempo- a la actualidad y muestra, a través de las acciones de los personajes, los afectos interiores

\footnotetext{
${ }^{4}$ El término, como un punto intermedio, de contrastes, lo emplea también en otros contextos: la vida de cada uno es, advierte, una tragicomedia (VII, 181); y, el hombre, trágico-cómico (VIII, 215).
} 
a las almas, las pasiones de los hombres. La novela es la categoría del diálogo ${ }^{5}$. Porque es este el que posibilita la convivencia entre almas: que se pongan en relación, dice, unos corazones con otros (I, 488-489). El tema de la novela es la actualidad como tal actualidad: la correspondencia de la obra con los hechos contemporáneos. Como en la épica (un género diferente) lo es el pasado: «Si las figuras épicas son inventadas, si son naturalezas únicas e incomparables que por sí mismas tienen valor poético, los personajes de la novela son típicos y extrapoéticos; tómanse, no del mito, que es ya un elemento o atmósfera estética y creadora, sino de la calle, del mundo físico, del contorno real vivido por el autor y por el lector» (I, 375), escribe en Meditaciones del Quijote para servirle, con la comparación, para dar con el elemento clave de la novela como género: esa actualidad. Con lo que la épica queda, en la meditación primera, como la manifestación opuesta a la novela. «Un arte apolíneo indiferente», de objetos eternos, invulnerable (I, 391). Porque su tema es el pasado ideal: no el pasado del recuerdo, sino la absoluta antigüedad. Es arcaísmo. Porque los griegos, explica, tuvieron un sentido racionalista de la estética: no separaron el valor poético de la dignidad metafísica: sólo podía ser poético para ellos aquello que había sido primero, lo que contenía en sí los principios y las causas (I, 370-372). Las figuras épicas son personajes únicos; no tipos, como en la novela. Son naturalezas heroicas, creadas por el pueblo que luego el rapsoda, en un trabajo de virtuosidad técnica (no creadora), evoca sin ansias de originalidad, como un artífice. Lo define en "Problemas culturales", en 1911: arcaísmo es la forma de producción literaria y científica que elige un pueblo en decadencia: se retiene el pasado, galvanizándolo, dotándolo de una falsa vigencia (I, 550). Luego, en Meditaciones del Quijote, precisa el género: es la forma literaria de la épica, que tiene como tema el pasado ideal, la absoluta antigüedad. La épica es arcaísmo. La Ilíada lo es, y con ella el nacimiento de la poesía. Porque los griegos no podían aceptar lo actual como posibilidad poética: frente al orbe épico de Ulises y Héctor, el suyo -explica Ortega- es un mundo decadente, una realidad sucedánea y decaída. Escribe: «Para los griegos son plenamente poéticas sólo las cosas que fueron primero, no por ser antiguas, sino por ser las más antiguas, por contener en sí los principios y las causas» (I, 371$372)$.

A principios del XX, advierte el madrileño, la novela está en decadencia. En "El obispo leproso", en 1927, afirma que es el único género literario que aún existe (III, 545), pero cada vez es más difícil dar con una buena obra: solo el talento no basta, porque la cantera (enorme pero finita) que es la novela se va agotando: «Existe en la novela un número definido de temas posibles. Los obreros de la hora prima encontraron con facilidad nuevos bloques, nuevas figuras, nuevos temas. Los obreros de hoy se

\footnotetext{
${ }^{5}$ En un ámbito más filosófico, Ortega definirá el diálogo, en su "Prólogo para alemanes", en 1934, como el logos desde el punto de vista del otro (VIII, 17).
} 
encuentran, en cambio, con que sólo quedan pequeñas y profundas venas de piedra» (III, 388-389). Es la gran hora de la decadencia. Pero, por ello, es también la ocasión excelente -cierra, así, optimista, su decálogo de imperativos de 1925- para conseguir la obra perfecta. Aunque sea difícil (III, 415). Porque espera, con la escasez de temas, un esfuerzo mayor del escritor en aquellos otros elementos, al margen de la trama, capaces de dar cuerpo a la novela (III, 390). El imperativo de la novela es, dice, la autopsia: «Nada de referirnos lo que un personaje es: hace falta que lo veamos con nuestros propios ojos» (III, 391). Es un género moroso, retardatario, que se recrea en la presentación de los personajes (III, 393-394). El argumento, lo descrito, apenas interesa. Basta con un mínimo de acción. Lo que vale es la descripción misma, lo más minuciosa posible, llena de detalles, como la puerta del baptisterio de Ghilberti en Florencia, que hace de la novela un orbe irreal, hermético, sin andamiajes a la vista, capaz de anestesiar al lector, de hacerle olvidar, absorto en ese nuevo mundo virtual, su realidad: «La táctica del autor ha de consistir en aislar al lector de su horizonte real y aprisionarlo en un pequeño horizonte hermético e imaginario que es el ámbito interior de la novela. En una palabra, tiene que apueblarlo» (III, 409). El hermetismo, señala, es la forma que adopta en la novela el imperativo genérico del arte: la intrascendencia (III, 412).

Aunque no apuntala su análisis de la novela con su presente, con lo que escriben los novelistas que le son contemporáneos, como síntoma de los cambios que abren el siglo XX. Para dibujar las grandes líneas de su tiempo, con una nueva mentalidad que se distancia, según él, de la anterior, la del siglo XIX, burguesa, utilitarista, recurre a los movimientos de vanguardia, de una manera muy general, sin apuntalar su teoría con obras concretas, sin abordar la cuestión del género, con referencias a su epistemología (como una racionalidad específica), pero que subordina a la dimensión ontológica de un arte (en pintura, poesía...) que se reconoce como autónomo; con una perspectiva muy amplia, desde el fin de la mímesis, que cambia radicalmente la relación del arte con el mundo físico. Deja a la novela fuera, sin ese hilo de conexión con su época, en el entramado de las vanguardias para el que él, en España, promovió la colección Nova Novorum. Sus referencias son Cervantes, Dostoievski o Stendhal. No los vanguardistas, que, aunque promociona, tampoco incluye en su análisis del arte nuevo. Pero los objetivos que piensa Ortega que se marcan las vanguardias en epistemología, capaces de aportar un conocimiento crítico, no ingenuo, en un periodo de incertidumbre, son también -aunque Ortega no lo desarrolla- los de la novela, de corte existencial, que se siente heredera del arte vanguardista, pero más preparada para desarrollar esa función de conocimiento del ser humano (de la existencia, como ser en el mundo, con las 
paradojas terminales, más que de la realidad) frente a las limitaciones de la ciencia o la razón pura moderna, que se olvidan del ser, como defiende Kundera ${ }^{6}$.

Pero con los géneros literarios la reflexión teórica implica en Ortega también una decisión propia para expresar su filosofía, y una justificación que enraíza la forma de sus trabajos en el fondo de su razón vital, que pivota en la revalorización de la circunstancia, que él mismo asume para su caso. En su "Anejo: en torno al «Coloquio de Darmstadt, 1951»" escribe que la filosofía no tiene un género en que expresarse. Y que es cada filósofo el que ha tenido que adecuar su pensamiento al género que ha creído más conveniente: «Acontece, en efecto, que a pesar de ser la filosofía una ocupación intelectual tan importante, no ha poseído nunca un genus dicendi, un género literario que le sea propio, adecuado y normal. Me refiero, claro está, a la filosofía en cuanto creación. Cada genial pensador tuvo que improvisar su género. De aquí la extravagante fauna literaria que la historia de la filosofía nos presenta» (IX, 638-639). Él optó por diversas formas que remiten al ensayo: un género que exige una unión perfecta entre el pensamiento y la forma en que se expresa (Regalado García, 1990: 104 y 207-208): el género olvidado de la literatura española: al que ningún español, hasta entonces, se dedica de forma sistemática. En Ortega con un sentido muy amplio, con diferentes registros con que presenta sus trabajos: artículos, de periódico o en revistas, prólogos, estudios, cursos, conferencias y brindis, que suponen una fragmentación en su pensamiento, pero que responden, como si constituyeran, con su rastro, una autobiografía (cfr. Martín, 1999: 40-41; Regalado García, 1990, 306), a la circunstancia propia del madrileño: la que siempre consideró su tarea, ser mentor espiritual en España -y luego también en América (cfr. Maharg, 1992: 15)-, que le obligó a llevar a la filosofía allí donde pudiera ser leída por un español medio ${ }^{7}$. La suya debía ser una filosofía ad usum hispanici. Porque Ortega, que como intelectual abre una nueva etapa en la España de comienzos del siglo XX que seguirán después otros muchos escritores,

\footnotetext{
${ }^{6}$ «Si es cierto que la filosofía y las ciencias han olvidado el ser del hombre, aún más evidente resulta que con Cervantes se ha creado un gran arte europeo que no es otra cosa que la exploración de este ser olvidado» (Kundera, 1987: 15).

${ }^{7}$ «La forma gradual aparente en que Ortega hizo pública su filosofía puede explicarse en parte como el resultado de un sopesar las posibilidades de éxito que se le impuso en el transcurso de toda una vida de servicio a España. Pero sólo en parte. Lo que he llamado forma gradual aparente se debió también a una falta de perspicacia en sus contemporáneos, lo cual no dejaba de ser un tributo a la sagacidad de Ortega en su percepción del problema de España. Si Ortega hubiese sido lo que no fue, un filósofo europeo, nuestra elucidación de su obra habría asumido una forma totalmente distinta, o habría sido incluso innecesaria. Pero era filósofo y español, y en 1914 esto significaba ser "filósofo in partibus infidelium" (Meditaciones del Quijote). Es decir, las mismas condiciones que hicieron su filosofía posible y necesaria garantizaban que esta filosofía permanecería invisible, y que más que mal entendida sería desatendida. Pero si no olvidamos que el principal objetivo de Ortega era conducir a España al siglo XX, y no escribir una Crítica de la razón práctica, tendremos más posibilidades de poder discernir la confusión que envuelve la génesis de su obra» (Silver, 1978: 18-19).
} 
El género literario: epistemología y justificación en Ortega y Gasset

sabe que sólo el periodismo, con la esclavitud del artículo, muchas veces frustrante, puede de verdad llegar a un público mayoritario. No hay mejor acceso. Periodismo y política, escribe José Carlos Mainer, son claves personales y profesionales para los escritores transformados, con el cambio de siglo, en intelectuales: una imagen que se mueve entre la frustración del trabajo apresurado e insatisfactorio y la convicción de una popularidad que sólo el periódico permite; entre el compromiso político y la imposibilidad de movilizar ideológicamente una sociedad insolidaria (Mainer, 1986: 66139.

El ensayo le exige una disposición del lenguaje que no es fácil, con las dos dimensiones de su prosa, que a veces, escribe Mermall (2000: 113-119), se confunden: el imperativo reformista o de salvación, motivado por la preocupación patriótica, y la búsqueda de un lenguaje capaz de comunicar el hallazgo de la razón vital e histórica, del que también es causa ${ }^{8}$. Unidas ambas por la idea de circunstancia, con la que sostiene que toda actividad humana queda inscrita en las coordenadas del tiempo y el espacio. Quiere mostrar su pensamiento, escribir su razón vital, pero le faltan antecedentes. Y tiene que hacerlo en español, consciente de que, a la vez que escribe, va abriendo con su reflexión metalingüística -aunque no tiene una teoría del lenguaje ${ }^{9}$, sino más bien, como escribe Cerezo Galán (1984: 378), una vena soterrada de inspiración que de tarde en tarde asoma- un camino nuevo en su lengua ${ }^{10}$ : "Yo sé muy bien -dice- las que he pasado muchas veces para pensar en español mi pensamiento personal» (IX, 76). Y lo asume como un hecho circunstancial: con el nivel cultural del español medio, o las imposiciones de la prensa, por ejemplo. Aunque su estilo asequible, el haber escrito en castellano, y sobre todo el incluir entre sus ideas hechos de su vida privada y pública, haya podido producir en algún lector una familiaridad, advierte Araya (1971: 18), inadecuada para ahondar en los problemas filosóficos que plantea. Tiene que expresar sobre el papel su propuesta de síntesis de razón y vida, que supone un camino -en la línea de la concepción humboldtiana del lenguaje como enérgeia, como actividad creadora (cfr. Carriscondo Esquivel, 2005)- que hasta entonces -advierte para que se le reconozca el primer puesto en la carrera- no ha indagado la filosofía. «El que haya que

\footnotetext{
${ }^{8}$ «La razón vital de la primera época se va incubando paulatinamente en la estética que Ortega elabora desde sus primeros escritos, proceso alimentado por la vivida experiencia de la escritura, expresión artística de una filosofía. El filósofo descubre en el libre juego de la imaginación un sentimiento de la vida (Lebensgefühl) ausente de la deducción trascendental de la razón pura y del apriorismo del deber moral de la razón práctica» (Regalado García, 1990: 57, n. 9)

9 «Ortega, hablando con propiedad, no escribió nunca una "teoría del lenguaje", ni siquiera dedicó a ello un escrito preciso; sus ideas sobre el lenguaje hay que entresacarlas de diversos textos en los que Ortega iba a otra cosa» (Martín, 1999: 293, n. 1)

${ }^{10}$ Ahí quedan las palabras de Julián Marías: «La lengua española se convierte, con Ortega, por primera vez, en una lengua filosófica -los hispánicos habían hecho poca filosofía, y sólo excepcionalmente creadora, y casi siempre en latín-. Y hay que decir que en una maravillosa lengua filosófica, tan apta para la filosofía como la que más» (cit. en Abellán, 1991: vol. V, p. 246).
} 
recurrir al hablar cotidiano y no exista en la historia entera de la filosofía una terminología adecuada para hablar formalmente del fenómeno vital no es tampoco casualidad», escribe (VII, 466). Se queda con el habla común, como si fuera un diálogo, para superar el carácter estático del lenguaje, en su búsqueda de una nueva terminología, pero anudada a la realidad, penetrándola, que transmita la fluidez de la lengua con la que expresar la dimensión vital que propone. Toma una palabra cotidiana y la maneja con toda su intensidad significativa directa, sin la herrumbrosidad de los nombres fatigados (VI, 358). Porque aunque hubiera querido echar mano de la terminología tradicional, escribe Araya (1971: 169), no hubiera podido: su preocupación le exige abrir un nuevo camino, con la metáfora -lo que no se puede aprender de los otros, un signo de genialidad, avisa Aristóteles en su Poética (59a)como fundamento de su trabajo. El filósofo, dice Ortega, «se encuentra ante la lengua en situación bastante dramática. Porque pensador es el que descubre, revela realidades nunca vistas antes por nadie» (IX, 635).

A su amigo Navarro Ledesma, cuando aún era muy joven, le confesaba que no se sentía seguro de su valor como escritor: que su estilo era mostrenco, y lo quería caliente, prieto y necesario, porque solo con un estilo caliente podría ser comprendido en España, que era una de las caras de su objetivo principal, y también una de las causas que lo llevaron a la prensa diaria, o al libro más divulgativo, más accesible, con la que podía aumentar muy significativamente el número de receptores de sus ideas (cfr. Zamora Bonilla, 2002: 42). Porque el afán de comprensión en cada una de sus propuestas iba más lejos que la exposición profunda y sistemática de su filosofía, que latía en un segundo plano, sin exhibirse. Como pensador, como escritor y como educador, las tres vocaciones con las que Rodríguez Huéscar dibuja su semblanza, Ortega remite a la conclusión de su Meditaciones del Quijote: a la función que se impone desde su propia circunstancia. Porque para las tres, en el punto en que se hacen una, da con un modo concienzudo con el que expresarse: un género en el que poder comunicar la verdad para hacerla fértil en la circunstancia (Rodríguez Huéscar, 1994: 55-59). Meditaciones del Quijote no es ciencia: es ensayo: la ciencia sin la prueba, dice. Riguroso con la verdad, pero sin la aridez de la demostración, que es la condición que se impone para comunicarla. Un género que va a ser también el de sus otros trabajos más importantes, que nacen de su filosofía pero que dirige la circunstancia. Porque cuando lo intentó con otros géneros, con una exposición más científica, o académica, para darle una forma cerrada a su sistema, con sus últimos libros, con el inacabado El hombre y la gente o la Aurora de la razón histórica, que no llegó a escribir, no fue capaz de expresarse, de mostrarse seguro. 
El género literario: epistemología y justificación en Ortega y Gasset

\section{Bibliografía}

ABELLÁN, José Luis (1991): Historia crítica del pensamiento español. Madrid, Espasa-Calpe.

ARAYA, Guillermo (1971): Claves filológicas para la comprensión de Ortega. Madrid, Gredos, 1971.

ARISTÓTELES (1995): Poética. Ed. Valentín García Yebra. Madrid, Gredos.

CAMPOMAR, Marta (2001): "Victoria Ocampo en la cultura del amor de Ortega y Gasset", Revista de Estudios Orteguianos, 3, pp. 209-290.

CARRISCONDO ESQUIVEL, Francisco M. (2005): "Biografía de dos temas orteguianos: la creatividad léxica-semántica y el diccionario", Revista de Estudios Orteguianos, 10/11, pp. 219-243.

CEREZO GALÁN, Pedro (1984): La voluntad de aventura, La voluntad de aventura. Barcelona, Ariel.

GARCÍA BERRIO, Antonio, y HUERTA CALVO, Javier (1992): Los géneros literarios: sistema e historia. Madrid, Cátedra.

KUNDERA, Milan (1987): El arte de la novela. Barcelona, Tusquets.

MAHARG, James (1992): José Ortega y Gasset. Madrid, Ediciones de cultura hispánica.

MAINER, José Carlos (1986): La edad de plata (1902-1939). Madrid, Cátedra.

MARTÍN, Francisco José (1999): La tradición velada. Ortega y el pensamiento humanista. Madrid, Biblioteca Nueva.

MERMALL, Thomas (2000): "Hacia una retórica de Ortega", Revista de Estudios Orteguianos, 1, pp. 113-119.

ORTEGA Y GASSET, José (1990): Meditaciones del Quijote. Ed. de Julián Marías. Madrid, Cátedra.

ORTEGA Y GASSET, José (1983): Obras completas. Madrid, Espasa-Calpe.

REGALADO GARCÍA, Antonio (1990) El laberinto de la razón: Ortega y Heidegger. Madrid, Alianza.

RODRÍGUEZ HUÉSCAR, Antonio (1994): Semblanza de Ortega. Barcelona, Anthropos.

SALAS FERNÁNDEZ, Tomás J. (1994): Los géneros literarios en el ensayo de Ortega: novela, teatro y poesía (tesis doctoral). Málaga, Universidad de Málaga.

SILVER, Philip (1978): Fenomenología y razón vital, Fenomenología y razón vital. Génesis de "Meditaciones del Quijote" de Ortega y Gasset. Madrid, Alianza. ZAMORA BONILLA, Javier (2002): Ortega y Gasset. Barcelona, Plaza \& Janés. 